\title{
Studies on Heat Flux Imparted on Thermal Insulation Inside Rocket Motor Containing Double Base Propellant
}

Rakesh Kumar Kalal1,*, Balesh Ropia², Himanshu Shekhar, Prashant Sudhir Alegaonkar4

Kalal RK (D) https: / / orcid.org/0000-0002-6810-547X

Ropia B (iD https: / /orcid.org/0000-0003-4626-2965

Shekhar H (D) https: / /orcid.org/0000-0002-9403-4070

Alegaonkar PS (1) https: / / orcid. org/0000-0002-4670-1684

\section{How to cite}

Kalal RK; Ropia B; Shekhar H; Alegaonkar PS (2019) Studies on Heat Flux Imparted on Thermal Insulation Inside Rocket Motor Containing Double Base Propellant. J Aerosp Technol Manag, 11: e3019. https://doi.org/10.5028/jatm.v11.1058

ABSTRACT: Thermal insulation inside the rocket motor experience severe pressure and temperature conditions. Experimental determination of heat flux imparted to thermal insulator inside the rocket motor during the static firing is a challenging task. This paper reports experimental determination of heat flux for double base propellant (DBP) in small rocket motor. It includes development of experimental rocket motor, adaptation of water-cooled heat flux sensor on rocket motor, required instrumentation for heat flux time recording and analysis of data. Data are recorded in real time for double base propellant combustion up to the pressure level $\sim 3.6 \mathrm{MPa}$. Average heat flux imparted to the rocket motor casing is found in the range of $230-300 \times 10^{4} \mathrm{~W} / \mathrm{m}^{2}$. Heat flux inside the rocket motor varies nearly linear with pressure. A correlation between the heat flux and pressure is also established for measured pressure range.

KEYWORDS: Heat flux, Rocket motor, Thermal insulation, Double base propellant.

\section{INTRODUCTION}

In propulsion systems, combustion chamber of propulsion unit is subjected to high pressure and high temperature simultaneously. Both affect thickness of casing and their synergetic effects results in failure of rocket motors for inadequate design input.

Double base propellants (DBP) generates combustion gas temperature around $2000-2500{ }^{\circ} \mathrm{C}$ under pressurized conditions (Davenas 1993; Kubota 2002). Rocket chamber is protected from high temperature of combustion gases by thermal insulators. Convection is the dominant mode of heat transfer for non-metallized solid propellants to the thermal insulators whereas convective and radiative mode contribute simultaneously for heat transfer to the thermal insulator from composite propellant combustion (Martin et al. 2013). However, as the burning time of rocket increases, the thin layer of thermal insulators is inadequate to control and restrict the rise in chamber wall temperature. So silica based insulator like EPDM sleeves are placed inside rocket motor chambers (Davenas 1993; Twichell and Keller Jr 1976). Advent of

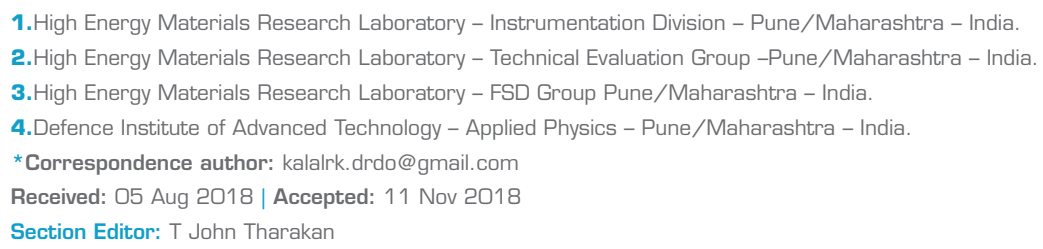


composite propellants with high combustion gas temperatures and case bonding technology, the inert thermal insulation layer thickness becomes an unwanted dead weight. Weight penalty used to be very high for large size rocket chamber and an attempt is made to put just an optimum thickness of thermal insulation layer thickness inside rocket motor chamber. To practically determine and optimize insulation thickness, rocket is fired in static mode and is extinguished after firing. However, theoretical determination of insulation thickness needs calculation in simulated rocket conditions. Similar is the situation for rocket nozzle insulation. Simulation of thermal loading on rocket chamber needs dedicated and exclusive instrumentation set-up for the measurement of high heat flux observed in actual rocket operations. Thermocouples based method for transient heat flux measurement is well established (Ellison et al. 1969; Coy 2008; 2010).

Burning rate of the propellant is decided by the heat feedback from the flame to the condensed phase of the propellant. For theoretical computation and analysis of the burning behavior there is a requirement of actual heat flux generated by the combustion of propellant inside the combustion chamber at operating pressure of rocket motor (Litzinger et al. 2000). For DBP heat balance studies from gas phase to burning surface are described by Kakami and Tachibana (2015).

Heat energy generated by combustion of propellant is the major parameter to be measured. In rocket propulsion, heat flux generated by the combustion of the propellant varies from 200 to $2500 \times 10^{4} \mathrm{~W} / \mathrm{m}^{2}$ (Twichell and Keller $\mathrm{Jr}$ 1976). Radiative heat flux incident on thermal insulator and propellant condensed surface are well characterized and demonstrated (Martin et al. 2013). Total heat flux (convective and radiation) measurement inside the rocket motor and its plume leads to information about heat energy generated by the propellant. Gaseous phase of the burning propellant gives heat feedback to the condensed phase of propellant for burning. Heat flux of the same order is experienced by thermal insulation thickness used for protection of casing from severe environment inside the rocket motor. In this paper an attempt is made to measure and study total heat flux generation by the combustion of DBP inside the metallic rocket casing during static firing.

\section{MEASUREMENT THEORY}

Presently, different types of heat flux sensors are available for the measurement of heat flux. The main class of heat flux sensors are conduction based, convection based and radiation based. For experimental determination of high heat flux for long duration water-cooled mixed mode heat flux sensors are preferred. This sensor responds to convection as well as radiation mode of heat transfer. Heat flux sensor is fundamentally a differential thermocouple. Generally copper-constantan circular foil (Gandon Gauge) are used for the measurement of high heat flux of the order of $2500 \times 10^{4} \mathrm{~W} / \mathrm{m}^{2}$ (Kutz 2013; Gardon 1953; 1960). The circular foil heat flux sensors generate electrical (millivolt) output due to absorption of heat energy rate. A cylindrical metal heat sink around the perimeter of thin circular metal foil sensing element forms a reference thermocouple junction as being different thermoelectric potentials of dissimilar metals. Another thermocouple junction is formed at the center of the thin foil using a fine wire of the similar material as the heat sink. When the sensing element is exposed to a heat source, the surface of the thin circular foil absorbs heat energy and heat is conducted radially to the heat sink, i.e. cylindrical metal. A parabolic temperature gradient between the center and the edge of the thin foil is established due to heat absorption. A pictorial representation of the heat flux sensor is shown in Fig. 1. This temperature gradient generates a thermoelectric potential, $E$, between the center wire and the heat sink which is proportional to the heat flux $q$. For a copper-constantan foil with a given diameter and thickness, the potential $E$ is linearly proportional to the heat flux $q$ absorbed by the foil. It can be represented mathematically by Eq. 1:

$$
E=K q
$$

where $K$ is calibration or sensitivity constant determined experimentally with calibration procedure (ASTM E511-01 2001). 


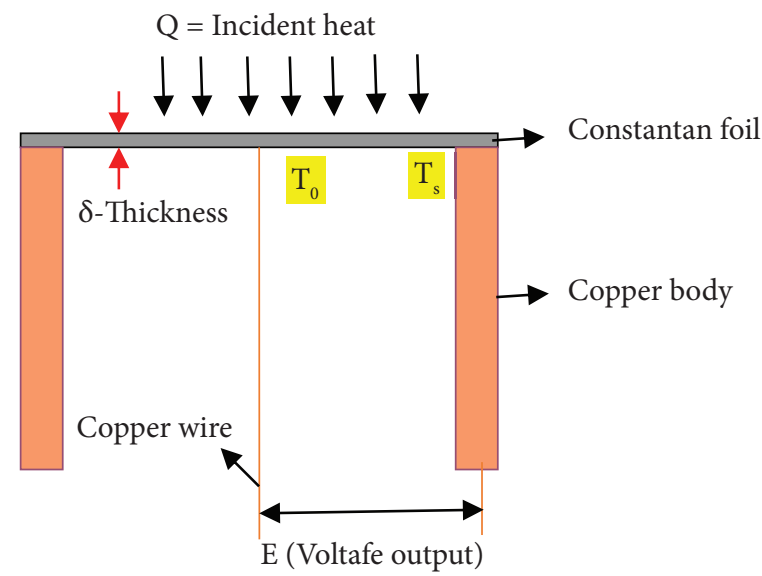

Figure 1. Heat flux sensor/Copper-Constantan foil schematic.

\section{EXPERIMENT AND MATERIAL}

To investigate the heat flux on the inner surface of rocket motor during the static test a small rocket motor is designed for withstanding maximum internal pressure of $10 \mathrm{MPa}$. This motor has internal volume $\sim 3.0 \times 10^{-4} \mathrm{~m}^{3}$. In the motor casing, two through holes are drilled with $5 \mathrm{~mm}$ diameter drill bit, to have direct contact with flame (convective mode heat transfer) and hot gases generated by combustion of propellant, for the heat flux and pressure monitoring during the test respectively. A special adaptor is designed to fix the heat flux sensor and water-cooling assembly on the motor. Nozzle with throat diameter of $12 \mathrm{~mm}$ is used to maintain the inside average pressure 2-3 MPa. Four cylindrical grains of DBP with Nitrocellulose (NC) 55-60\%, Nitroglycerine (NG) 35-40\% and Carbamite 2-3\% with beta-lead resorcylate (1-1.5 Part) composition are selected for testing. Propellant grain details are given in Table 1. All four propellant grains have same chemical compositions and geometry. The density of propellant was $1.63 \mathrm{~g} / \mathrm{cc}$. In these experiments uninhibited propellant is used for regressive burning. It was initiated with standard gun powder composition.

Table 1. Propellant grains details.

\begin{tabular}{|c|c|c|c|c|}
\hline Grain $\mathrm{n}^{\circ}$ & OD $(\mathbf{m m})$ & Length $(\mathrm{mm})$ & Mass $[\mathbf{k g}]$ \\
\hline DBP1 & 39.66 & 20.36 & 55.86 & 0.083 \\
\hline DBP2 & 39.54 & 10.7 & 59.8 & 0.111 \\
\hline DBP3 & 39.64 & 10.7 & 60.0 & 0.113 \\
\hline DBP4 & 39.24 & 10.7 & 60.0 & 0.113 \\
\hline
\end{tabular}

A strain gauge type pressure sensor calibrated up to the range $10 \mathrm{MPa}$, response time $\leq 1 \mathrm{~ms}$ and full scale voltage output of $10 \mathrm{~V}$ is used. Heat flux sensor calibrated up to $2246 \times 10^{4} \mathrm{~W} / \mathrm{m}^{2}$ for full scale output of $10 \mathrm{mV}$, response time $\sim 20 \mathrm{~ms}$ with sensitivity $224.6 \times 10^{4} \mathrm{~W} / \mathrm{m}^{2} / \mathrm{mV}$ is used. Calibration curve for full range of the sensor is shown in Fig. 2 . It indicates a good linearity for full range. Heat flux sensor assembly on the rocket motor is shown in Fig. 3. After assembling the propellant with the rocker motor, complete assembly is mounted on a test stand for static testing. This arrangement is shown in Figs. 3 and 4 whereas leak proof heat flux sensor assembly is shown in Fig. 5. The static firing is conducted remotely from control room located at $200 \mathrm{~m}$ from the test bed. Data of pressure and heat flux is acquired in control room. 


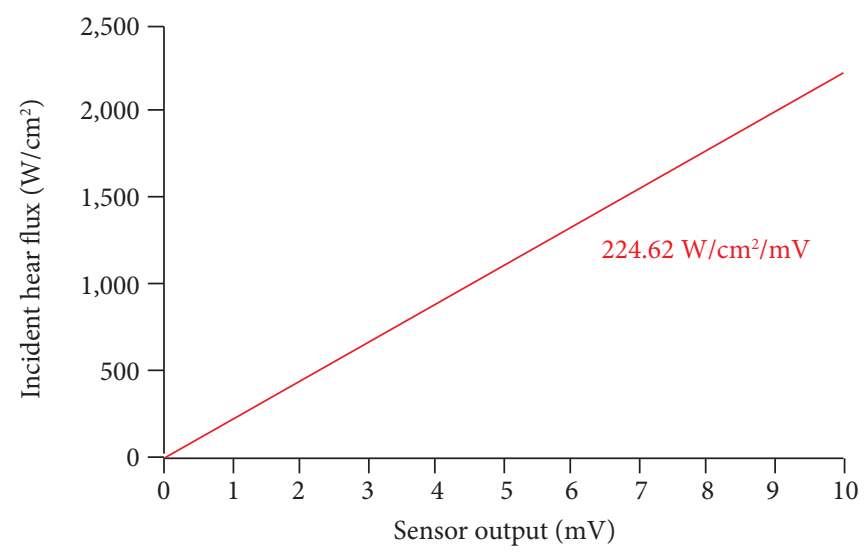

Figure 2. Heat flux sensor calibration curve.

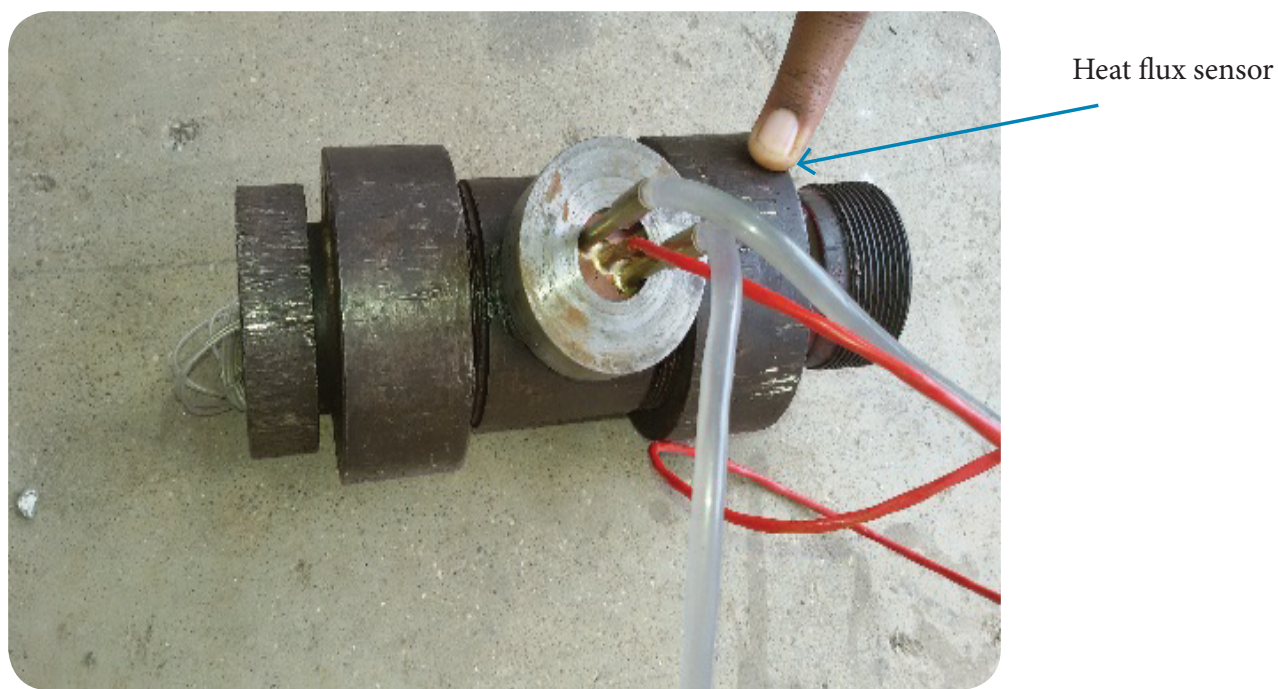

Figure 3. Assembly of heat flux sensor on rocket motor

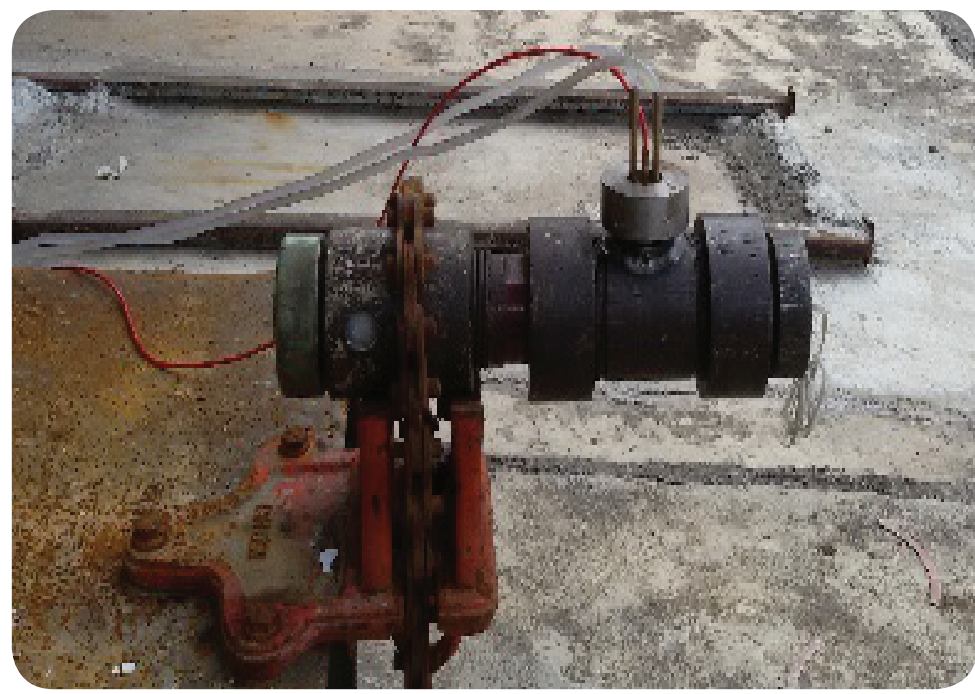

Figure 4. Rocket motor mounted on stand. 


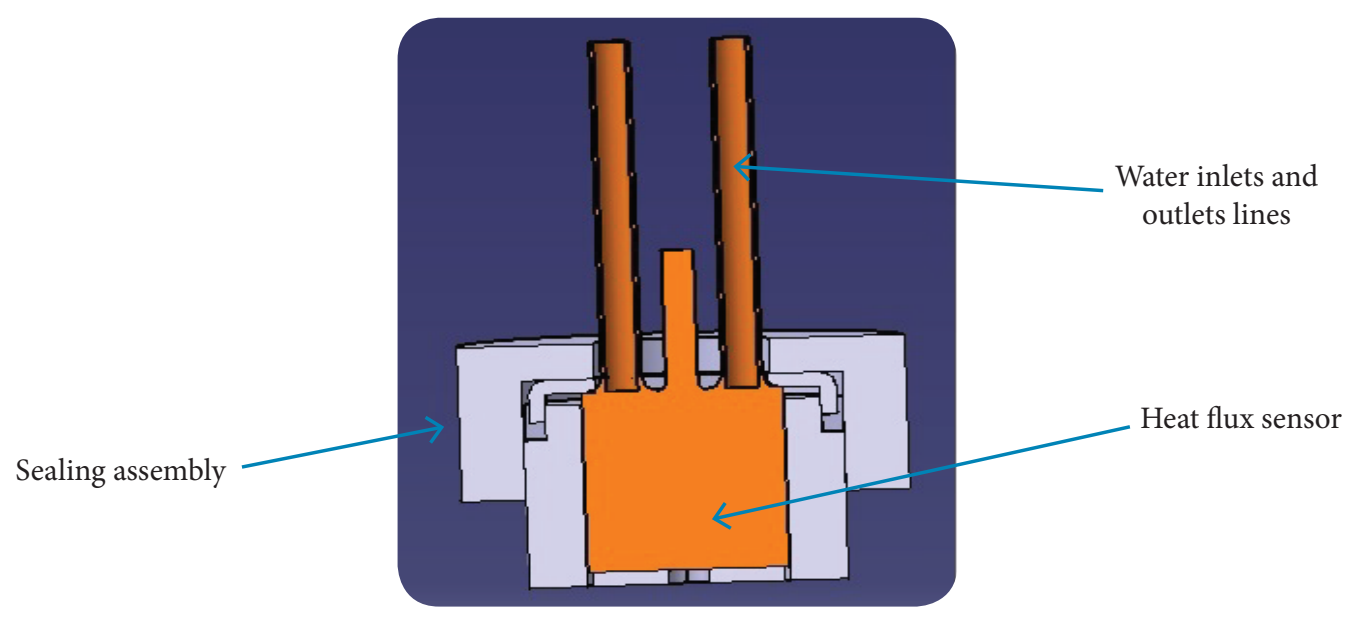

Figure 5. Leak proof heat flux sensor assembly - 3D view.

\section{RESULTS AND DISCUSSION}

During the firing, it is observed that there is no gas leakage from both the measurement ports. It is also observed physically that there is no erosion in graphite nozzle during the firing as the total duration is $\leq 0.6$ s. Real time pressure as well as heat flux data is recorded with time. Sampling rate for time base of the memory recorder was adjusted at $1 \mathrm{~kg}$ samples/s for recording of pressure and heat flux output. All pressure vs. time and heat flux vs. time data for same composition are shown in Figs. 6 and 7, respectively. Recorded raw heat flux data exhibits oscillations and noise hence data was smoothed with 30 point running average. An initial higher pressure kink is observed for pressure-time profile of DPB2 to DBP4 whereas for DBP1 has comparatively lower pressure kink. It may be due to the initial available free volume inside the combustion chamber, which is lower for DPB2 to DBP4 grains than DBP1 grain. It is evident from the recorded pressure-time and heat flux-time profiles that the pressure and heat flux follow the same trends during the combustion and signal duration is also approximately the same. Also, this profile shows that the heat flux at a given time is higher if the pressure is high inside the chamber. Computed data for pressure, heat flux and duration of burning are shown in Table 2. Total average heat flux obtained from these static trials exhibits good repeatability.

Table 2. Average pressure, burn time and average heat flux data.

\begin{tabular}{|c|c|c|c|}
\hline Grain $\mathrm{n}^{\circ}$ & Average pressure (MPa) & Web burn time $(\mathrm{s})$ & Average heat flux $\left[\times 10^{4} \mathbf{W} / \mathrm{m}^{2}\right]$ \\
\hline DBP1 & 2.363 & 0.41 & 246 \\
\hline DBP2 & 2.285 & 0.51 & 290 \\
\hline DBP3 & 2.216 & 0.51 & 231 \\
\hline DBP4 & 2.344 & 0.48 & 254 \\
\hline
\end{tabular}

From Table 2 it is clear that the average heat flux for DBP is in the range of $230-300 \times 10^{4} \mathrm{~W} / \mathrm{m}^{2}$. A time lag is observed in both profiles. As the pressure sensor is more sensitive, initial ignition pressure peak is observed in P-t profile but heat flux sensor does not respond for the same. It is due to the slow response time of heat flux sensor of the order of $\sim 20 \mathrm{~ms}$, whereas for pressure sensor it is $\leq 1 \mathrm{~ms}$. But later on it follows the trends of pressure profile. The residual hot gases in the rocket chamber continue to give sufficient heat to the sensor even after all burn point. The role of heating of heat flux sensor after complete consumption of propellant cannot be ruled out. But the observation is in line with rocket operation. 


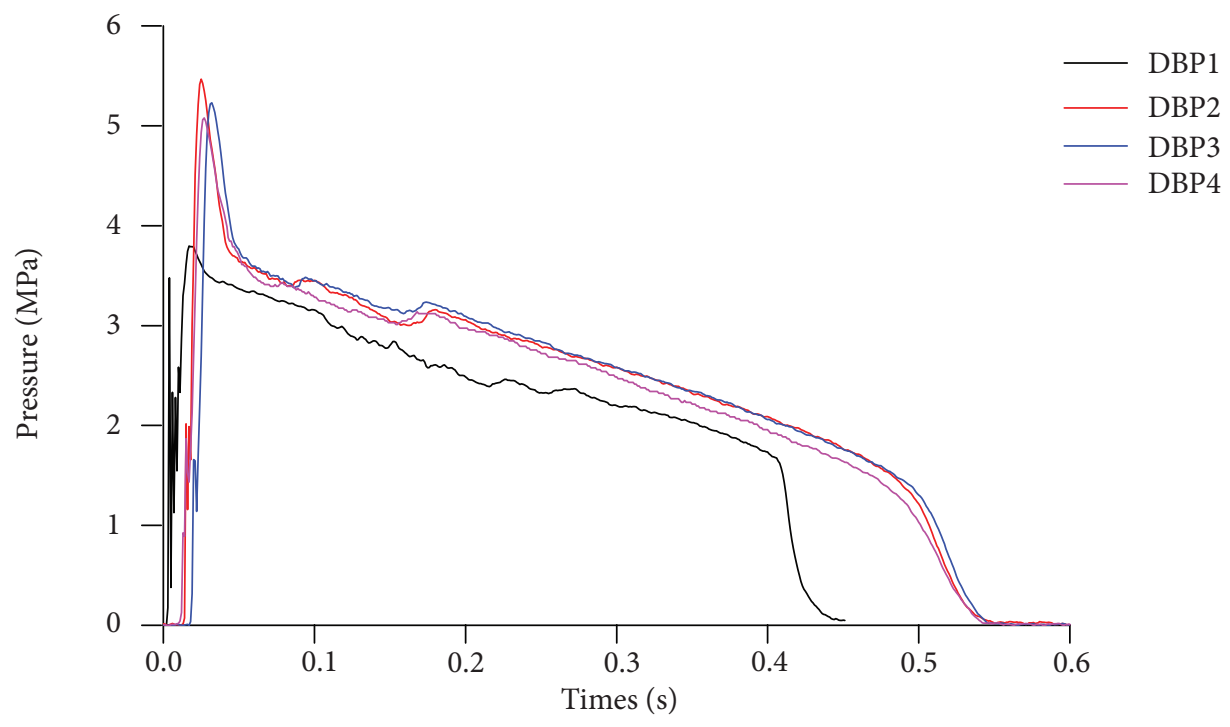

Figure 6. Pressure-time profile for DBP 1, DBP2, DBP3 and DBP4.

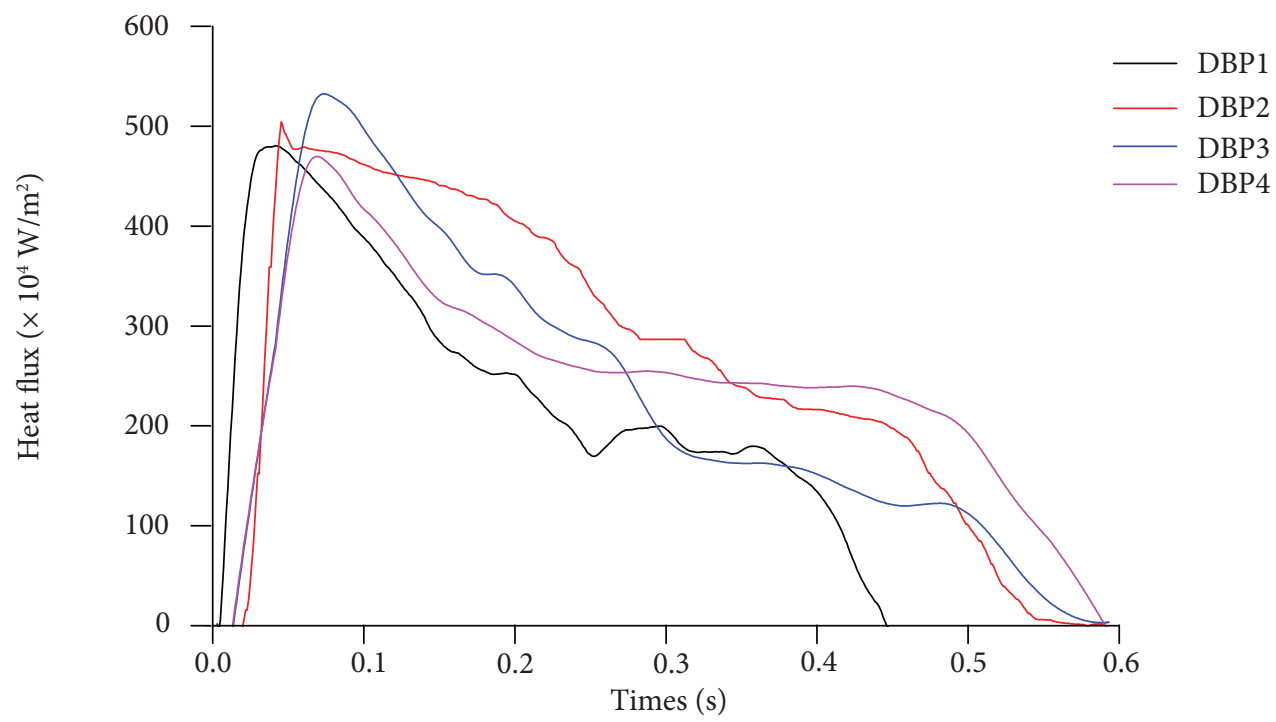

Figure 7. Heat flux-time profile for DBP1, DBP2, DBP3 and DBP4.

From heat flux-time record, it is also observed that there is a slight variation in the measured data. It may be due to the higher pressure generation by DBP2, DBP3 and DBP4 and turbulence in the flame during the combustion inside the chamber.

Further heat flux-pressure data are also plotted and analyzed from the recorded data. For generation of this curves, transient section of the pressure-time and heat flux-time is not accounted. These curves clearly indicate that it is possible to generate a linear relation between the heat flux and pressure. A best-fit linear curve is generated using least square method for all four experiments. All four linearly fitted curves can be plotted together for heat flux vs. pressure as shown in Fig. 8. From the curve, it is also observed that it is not passing through the origin and have a negative intercept on heat flux axis. When mathematically intercept is made zero, than a generalized equation is generated for all the four different data and takes final form of $\mathrm{Q}\left(\mathrm{W} / \mathrm{m}^{2}\right)=116.43 \times 10^{4} \mathrm{P}(\mathrm{MPa})$ for average curve, where constant having the dimension of $\left(\mathrm{W} / \mathrm{m}^{2}\right) / \mathrm{MPa}$. 


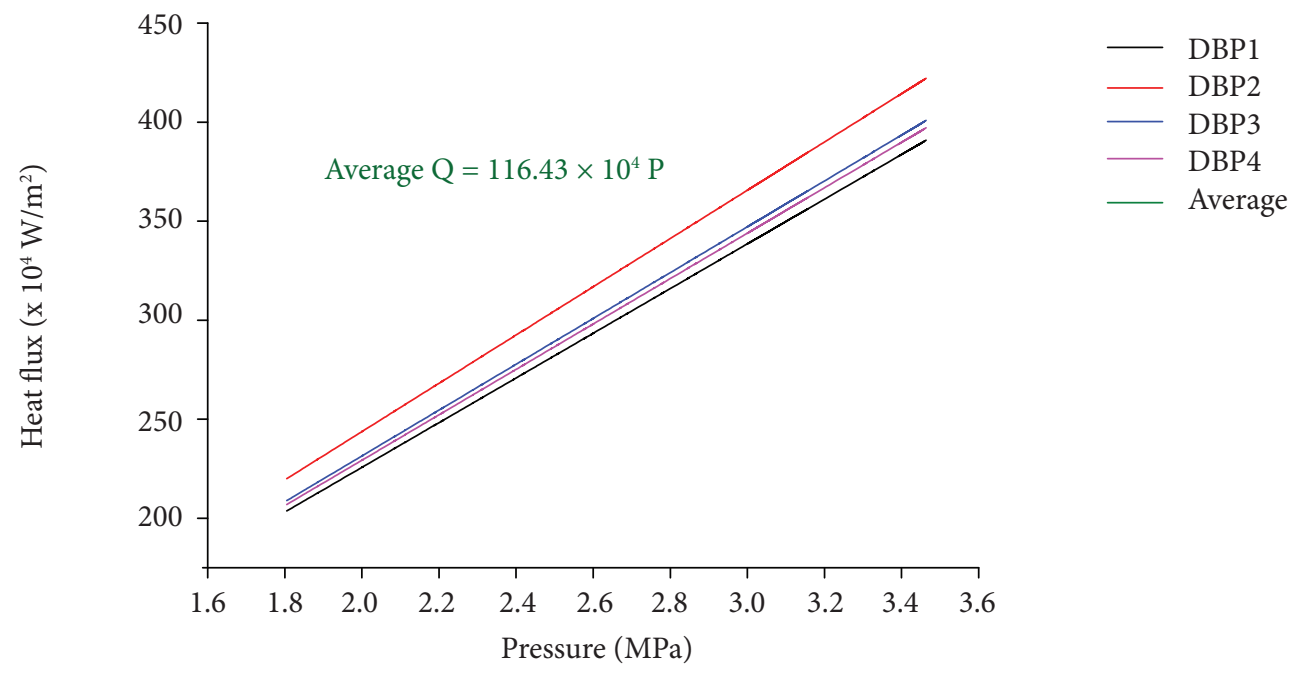

Figure 8. Heat flux- pressure profile (fitted curves).

\section{CONCLUSION}

With these experiments, the feasibility to record heat flux during static firing of rocket motor is established. The consistency and repeatability of measurement is proved by four firings of DBP. The practical determination of heat flux matches well with the earlier reported range of values. The relation between pressure and heat flux is also developed, which can be extrapolated to other type of propellants. The adequacy of thermal insulation can also be correlated with pressure. It is clear that thermal insulator used inside the rocket motor is exposed to average heat flux of $230-300 \times 10^{4} \mathrm{~W} / \mathrm{m}^{2}$ for double base propellant. It can be inferred that the average heat flux experienced by the surface of rocket motor is of the order of $230-300 \times 10^{4} \mathrm{~W} / \mathrm{m}^{2}$. Heat flux varies nearly linear with pressure inside the rocket motor. Hence for higher pressure, higher heat flux is observed and insulation consumption will be higher.

\section{ACKNOWLEDGEMENTS}

The authors acknowledge Director HEMRL for permitting to publish this work. The authors are also thankful to Shri DK Kankane for his continuous support and guidance.

\section{AUTHOR'S CONTRIBUTION}

Conceptualization, Kalal RK, Ropia B; Methodology, Kalal RK, Ropia B, Shekhar H, Alegaonkar PS; Investigation, Kalal RK, Ropia B; Writing - Original Draft, Kalal RK; Writing - Review and Editing, Shekhar H, Alegaonkar PS; Supervision, Shekhar H, Alegaonkar PS.

\section{FUNDING}

There are no funders. 


\section{REFERENCES}

ASTM E511-01 (2001) Standard test method for measuring heat flux using a copper constantan circular foil, heat-flux gage. West Conshohocken: ASTM International. https://doi.org/10.1520/E0511-01

Coy EB (2008) An efficient method for calculating surface temperature and heat flux based on embedded temperature sensors. Presented at: 26th AIAA Aerodynamic Measurement Technology and Ground Testing Conference; Seattle, USA. https://doi.org/10.2514/6.2008$\underline{3952}$

Coy EB (2010) Measurement of transient heat flux and surface temperature using embedded temperature sensors. Journal of Thermophysics and Heat Transfer 24(1):77-84. https://doi.org/10.2514/1.45075

Davenas A (1993) Solid rocket propulsion technology. 1st ed. Avon: The Bath Press.

Gardon R (1953) An instrument for the Direct Measurement of Intense Thermal Radiation. The Rev of Sci Instruments 24(5):336. https://doi.org/10.1063/1.1770712

Gardon R (1960) A transducer for the measurement of heat flow rate. Journal of Heat Transfer 82(4):396-398. https://doi. org/10.1115/1.3679968

Ellison JR, Binder HI (1969) Evaluation of a heat flux measurement system. (TR-69-238). AFRPL Technical Report.

Kakami A, Tachibana T (2015) Heat balance evaluation of double-base solid propellant combustion using thermography and laser heating on a burning surface. Aerospace Science and Technology 47:86-91. https://doi.org/10.1016/j.ast.2015.09.013

Kubota N (2002) Propellants and explosives. Thermochemical aspects of combustion. Weinheim: Wiley-VCH GmBH.

Kutz M (2013) Handbook of Measurement in Science and Engineering. Hoboken: John Wiley \& Sons.

Martin HT, Houin RW, Ferrara PJ, Degges MJ, Cortopassi AC, Boyer JE, Kuo KK (2013) A novel radiative heat flux Measurement technique for Combustion products flowing in Solid rocket motors. International Journal of Energetic Materials and Chemical Propulsion 12(3):183-196. http://10.1615/IntJEnergeticMaterialsChemProp.2013001451

Twichell SE, Keller Jr BR (1976) Solid rocket motor internal insulation. (NASA-SP-8093). NASA Technical Report.

Litzinger TA, Lee YJ, Tang CJ (2000) Experimental Studies of Nitramine/Azide Propellant Combustion. In: Yang V, Brill TB, Ren WZ, editors. Solid Propellant Chemistry, Combustion, and Motor Interior Ballistics. Reston: AIAA. p. 355-377. 